\title{
不飽和浸透の基本的特性とヒステリシスを 考虚した新しい、不飽和浸透理論 \\ Studies On the Fundamental Characteristics and the Proposed New Equations of Unsaturated Infiltration Considering Hysteresis
}

\author{
北海道大学工学部 正員 山田 正 T.Yamada \\ 北海道大学大学院 学生員 小林 稔 M.Kobayashi
}

\section{1.はじめに}

雨水の土䁃中の挙動に関するいくつかの野外実測では、土墡水分の動きが放射性物質などのトレーサー による水の実質の動きよりも 1 析以上速い事が知られている21.31。一方、不飽和土堙中での水分移動に関 して、同一のボテンシャル勾配においても定常時に比べて吸水時には浸透しにくく脱水時には浸透し易い というヒステリシス現象が存在するが、この現象の取扱については脱水時と吸水時とで土の特性を表す関 係に別々の曲線を与えることによって通常行われてきた。しかし、著者らは本来、土堙の特性は定常状態 において測定されたものを用いるべきであり、ヒステリシス現象は基碄方程式の解の特性として捉えるべ きものであると考えている。

以上の事柄を背景とし、本研究は土壤中の雨水の浸透現象を取り扱うのに従来使用されてきた不飽和の 浸透方程式(Richardsの式あるいはKluteの式)を再検討し、解の持つ特性とその水文学的意義を明らかにす ること、さらにヒステリシス効果を内包した新しい不飽和浸透の基碟式を提案し、その適用性や新しい方 程式の解の持つ物理的意味を明らかにすることを目的としたものである。

\section{2. 不飽和浸透方程式の持つKinemat ic wave特性}

鉛直一次元に関するKluteの式である(1)式を用い降雨の鉛直浸透における解の特性を解析的に検討した。 また、不飽和透水係数の関係は(2)式に示す経験式を用いる。

$$
\begin{aligned}
& \frac{\partial \theta}{\partial t}+\frac{d k(\theta)}{d \theta} \frac{\partial \theta}{\partial z}=\frac{\partial}{\partial z}\left\{D(\theta) \frac{\partial \theta}{\partial z}\right\} \\
& k(\theta)=a \theta^{m}
\end{aligned}
$$$$
\text { ここで } \theta \quad: \text { 体積含水率 }
$$$$
\mathrm{k}(\theta): \text { 不飽和透水保数 }
$$

$\psi \quad$ :毛管ボテンシャル $D(\theta)$ : 水分拡散係数 $\mathrm{a}, \mathrm{m}$ : 係数

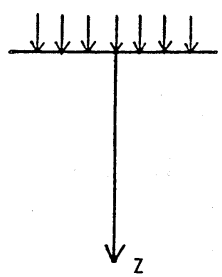

$\vee_{z}$

今、士堙表面に一定強度の散水をある時間与えた後、打ち切ると、散水終了後しばらくの間は土靖表面 における境界条件の影響を強く受けているが、土 中に十分深く浸透した雨水は次第にKinematic wa veとしての特性示し始め、その波速は(1),(2)式 より次式で示される。

$$
\frac{\mathrm{dk}(\theta)}{\mathrm{d} \theta}=\mathrm{ma} \theta^{\mathrm{m}-1}
$$

一方、重力水としての水粒子自身の移動速度は真

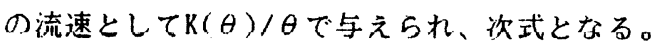

$$
\frac{k(\theta)}{\theta}=a \theta^{m-1}
$$

(3)，(4)式よりKinematic waveとしての波速は、

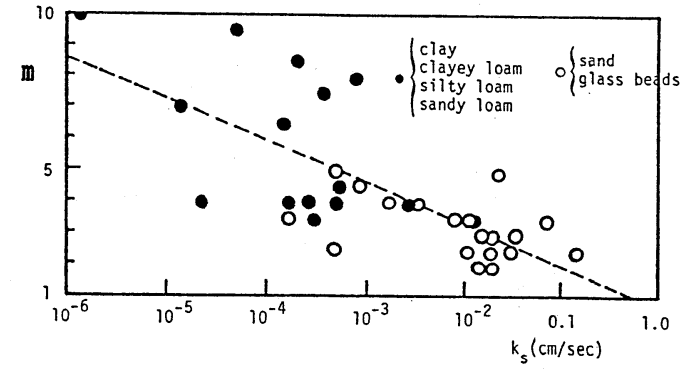

図-1（2）式の $\mathrm{m}$ と飽和透水係数 $\mathrm{k}$ っとの関係 (西垣“より)

水粒子の赛質の移動速度よりも $\mathrm{m}$ 倍大きくなって 
いることがわかる。図-1は西垣4によってまとめ られた様々な土爀に対する $\mathrm{m}$ の值であるが、この 図より砂質土は3-6、粘性土は4-10の值を取ること がわかる。これより土中深く浸透した水分量パタ ーンの降下速度(Kinematic waveの波速)はトレー サーの降下速度 (水粒子の実質の移動速度)に比べ て3ー10倍速いことになる。表-1はAneblomら ‘)によ ってまとめられたトレーサーの降下速度 (True ve

\begin{tabular}{|c|c|c|}
\hline Site Velocity & $\begin{array}{r}\text { True velocity } \\
(\mathrm{m} / \mathrm{mon} \text { th) }\end{array}$ & $\begin{array}{r}\text { Apparent velocity } \\
\text { (m/month) }\end{array}$ \\
\hline $\begin{array}{l}\text { Gronhoj } \\
\text { (Andersen \& } \\
\text { Sevel 1974) }\end{array}$ & 0.4 & $3-3.5$ \\
\hline $\begin{array}{l}\text { Tärnsjö } \\
\text { (Aneblom \& } \\
\text { Persson 1978) }\end{array}$ & $\sim 0.5$ & $1.5-2.5$ \\
\hline
\end{tabular}

表-1 トレーサーと水分量の移動速度の野外実測值 (Aneblomら2!より) locity)と水分量パターンの降下速度 (Apparent velocity)の野外実測值を比較したものであるが、これを 見るとその速度の違いは3-9倍程度となっており、上記の考え方の正当性を裹づけることができる。以上の 事より不飽和浸透流のKinematic wave特性が今までに観測されている、トレーサーの移動速度と水分量分 布の移動速度との間の異常に大きいズレの原因になっていると結論出来る。

\section{3.ヒステリシス効果を内包した新しい不飽和浸透方程式の解析}

\section{1 新しい基礎式の誘導}

ここでは、土の特性を表す $\psi-\theta$ 関係や $\mathrm{K}(\theta)-\theta$ または $\mathrm{K}(\psi)-\psi$ 関係としては定常状態において得られ る一価関係を入力として用いる。これに対し、水分フラックス $\vec{q}$ を新たに次式で表す。

$$
\begin{aligned}
& \vec{q}=\left(q_{x}, q_{y}, q_{z}\right) \\
& q_{x}=-k_{x}(\theta) \frac{\partial \psi}{\partial x}-\tau \frac{\partial q_{x}}{\partial t} \\
& q_{y}=-k_{y}(\theta) \frac{\partial \psi}{\partial y}-\tau \frac{\partial q_{y}}{\partial t} \\
& q_{z}=-k_{z}(\theta) \frac{\partial(\psi-z)}{\partial z}-\tau \frac{\partial q_{z}}{\partial t}
\end{aligned}
$$

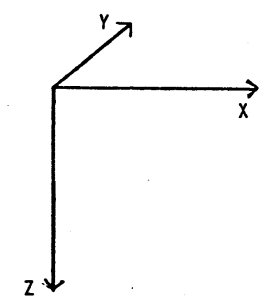

ここで、てはヒステリシスの効果による緩和時間を表す時定数である。(6)式では不飽和領域にまで拡張 されたDarcy則に、右辺第二項が新しく付け加わっている。(6)式の右辺第二項は、ポテンシャル勾配の変 化に対するフラックスの時間遅れを表しているが、これにより同一ポテンシャル勾配に対して脱水時には 浸透し易く浸潤時には浸透しにくいというヒステリシス効果を表現し得る。一方、土中水分の連続の式は

$$
\frac{\partial \theta}{\partial t}+\operatorname{div} \vec{q}=0
$$

であるから、(7)式に(6)式を代入して $\theta$ を従属変数にして表すと、

$$
\tau \frac{\partial^{2} \theta}{\partial t^{2}}+\frac{\partial \theta}{\partial t}+\frac{d k_{z}(\theta)}{d \theta} \frac{\partial \theta}{\partial z}=\frac{\partial}{\partial x}\left\{D_{x}(\theta) \frac{\partial \theta}{\partial x}\right\}+\frac{\partial}{\partial y}\left\{D_{y}(\theta) \frac{\partial \theta}{\partial y}\right\}+\frac{\partial}{\partial z}\left\{D_{z}(\theta) \frac{\partial \theta}{\partial z}\right\}
$$

となり、同様に $\psi$ を従属変数にして表すと次式となる。

$$
\begin{aligned}
& \tau C(\psi) \frac{\partial^{2} \psi}{\partial t^{2}}+C(\psi) \frac{\partial \psi}{\partial t}+\frac{d k_{z}(\psi)}{d \psi} \frac{\partial \psi}{\partial z}=\frac{\partial}{\partial x}\left\{k_{x}(\psi) \frac{\partial \psi}{\partial x}\right\}+\frac{\partial}{\partial y}\left\{k_{y}(\psi) \frac{\partial \psi}{\partial y}\right\}+\frac{\partial}{\partial z}\left\{k_{z}(\psi) \frac{\partial \psi}{\partial z}\right\} \\
こ & =て ゙ 、 C(\psi)=d \theta / d \psi
\end{aligned}
$$

(8),(9)式で左辺第一項が新たに加わった項であり、従来の不飽和浸透方程式が移流分散方程式であった のに対し、その特性に加えて電信方程式としての特性が加わるようになった。即ち、この方程式の数学上 の特性から不飽和浸透に新たに波動という特性が現れるようになったのである。 


\section{2 数値計算および計算結果}

本研究では、先に導いた(8),(9)式を鉛直一次元について数值計算を行った。計算では、ヒステリシスの 表現の確認や、 $\theta$ 分布や $\psi$ 分布の挙動の違いを見るために、 $\theta$ と $\psi$ とで独立に行われている。

ここで、体積含水率 $\theta$ に関する飽和一不飽和浸透の扱いについて説明をしておく。従来、 $\theta$ に関しては飽 和になるとその值はもはや変化しないとするためにKluteの方程式は飽和領域の浸透流を扱うことはできな いとされていた。しかし、飽和になってからも土の構造が多少変化することによって間隙率がわすかかが ら増加すると考元ることにより、飽和領域も扱えるようになる。具体的には水分搪散係数 $D(\theta)=\mathrm{K}(\theta) \mathrm{d} \psi$ $/ \mathrm{d} \theta$ において飽和領域になると $\mathrm{d} \theta / \mathrm{d} \psi=0$ となり $D(\theta)$ が無限大となるが、毛管ボテンシャル $\psi$ の場合の 飽和一不飽和浸透の解析に導入されている比貯留係数 $(\mathrm{Ss}=\mathrm{dn} / \mathrm{d} \psi \mathrm{n}$ :間隙率)をらこの場合も考慮すると、D $(\theta)$ は飽和においても無限大とはならす、解析が可能となる。

計算方法は空間的には中央差分をとり、時間的な連立微分方程式としてRunge-Kutta-Gill法を用いた。 計算は3ケース行っているが、それぞれのケースに与えた土壌の関係や初期条件、境界条件は以下に示され ている。また、いずれの場合も降雨(強度)Rはある一定時間(TR)与えた後、打ち切っている。

\section{2 .1 計算条件}

a)Case 1：土壤には砂を想定した関係を与え(図-2の実線)、初期値 には鉛直方向に一定値の分布を与えた。境界条件は、地表面で降雨 強度に等しい浸透速度を考え、底部は半無限状態としている。

b) Case 2: 土滾にはシルト・ロームを考えた関係を与え(図-8の上 端の実線)、その他はCase 1と同じ条件で計算を行った。

c)Case 3: Case 1と同じ砂の特性を与え(図-2の点線)、初期值は最 下部が地下水面となるような静止状態を与えた。地表面における条 件はCase 1, Case 2と同様に降雨強度と同じ浸透速度となるように設 定し、底部では不浸透層を考えている。

\section{2 .2 計算結果}

a)Case 1: 㘡-3,4,5はCase 1の計算結果を示すものであるが、これ らの図よりヒステリシス効果が非常に小さい場合 $(\tau=0.5 \sec$ の場合 )には $\theta$ とめの分布は同じ速度で伝わるが、ヒステリシス効果が大き くなると $(\tau=20 \sec の$ 場合)、 $\theta$ は $\psi$ よりも遅れることが解る。

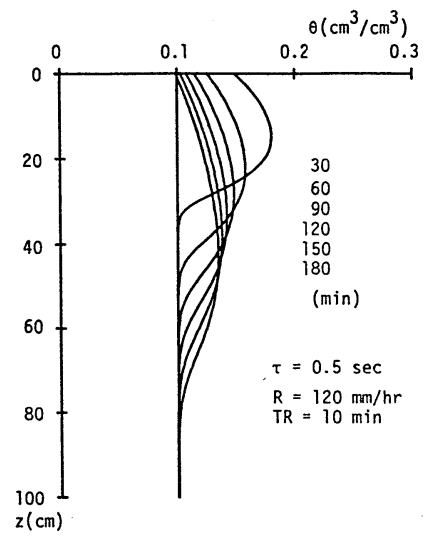

(a) $\tau=0.5 \mathrm{sec}$

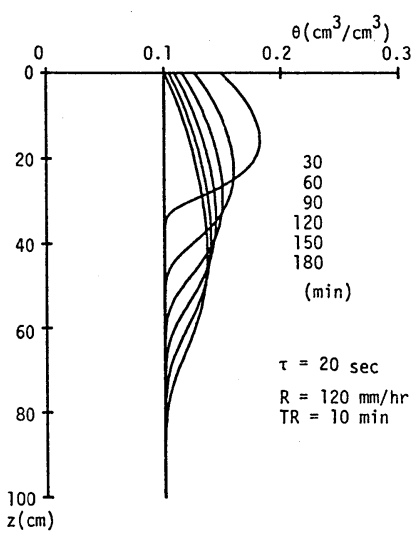

(b) $\tau=20 \mathrm{sec}$

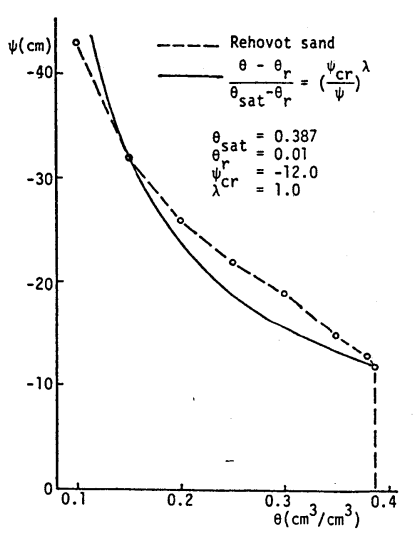

図-2 Case1とCase3の計算に用いた $\theta-\psi$ 関係

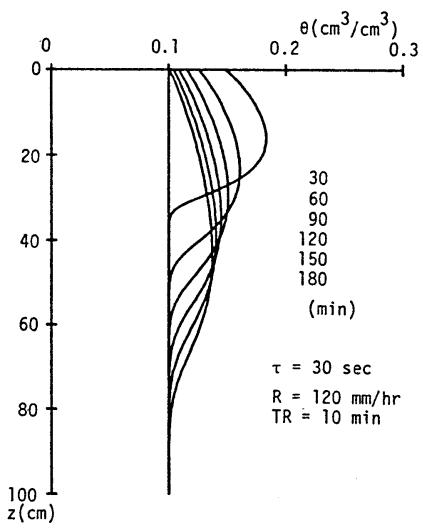

(c) $\tau=30 \mathrm{sec}$

図-3ｅ分布の時間変化(Case 1) 


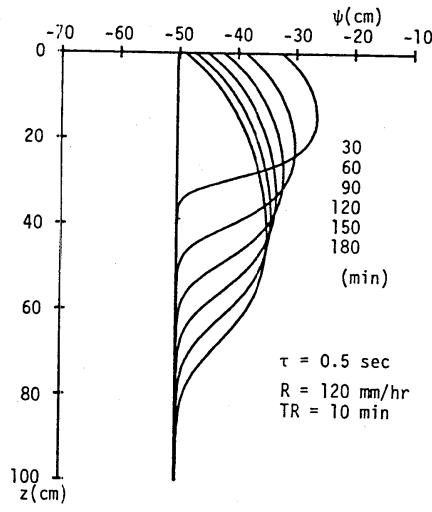

(a) $\tau=0.5 \mathrm{sec}$

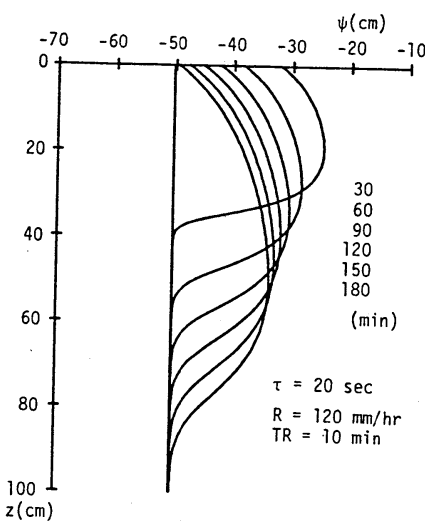

(b) $\tau=20 \mathrm{sec}$

図-4 $\psi$ 分布の時間变化(Case 1)

また、ヒステリシスの効果が非常に大きくなると $(\tau=30 \sec の$ 場合) $\psi$ の分布形は波動、あるいは段波の上うな伝わり方をし、 $\theta$ 上りも かなり速く下方八伝わるのがわかる。図-5は2つの独立した計算によ り得られた、ある一地点での $\theta$ といの挙動を示すものである。この 図より $\theta-\psi$ 関係には、吸水時と脱水時にヒステリシスカーブを示し ており、本研究で提示した新しい方程式の有用性を確認することが できる。

b)Case 2: 図-6,7,8はCase 20計算結果を示すものであるが、これ らの罒よりシルト・ロームの場合でも、Case 1で計算した砂の場合 と同様の傾向を示し、ヒステリシスルーブも同様に描くことができ る。また、ての值は砂の場合よりも大きな值で計算しなくてはヒス テリシス効果が顕著に現れなかった。
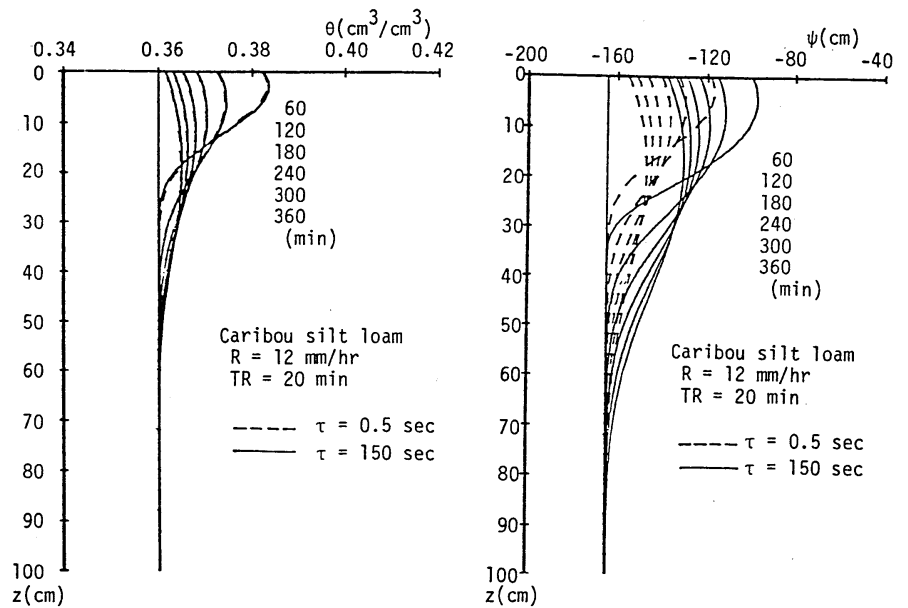

図-6 $\theta$ 分布の時間变化(Case 2) 図-7 $\psi$ 分布の時間变化(Case 2)

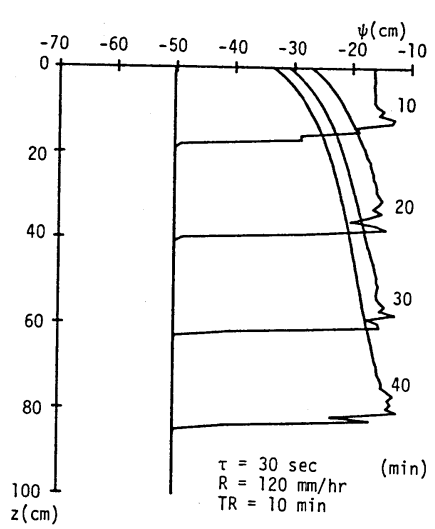

(c) $\tau=30 \mathrm{sec}$

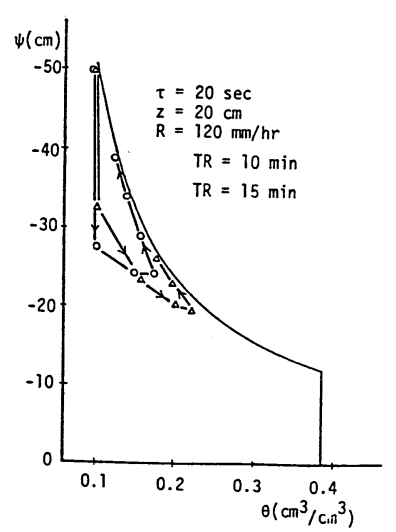

困-5 Case1の計算結果による $\theta-\psi$ 関係

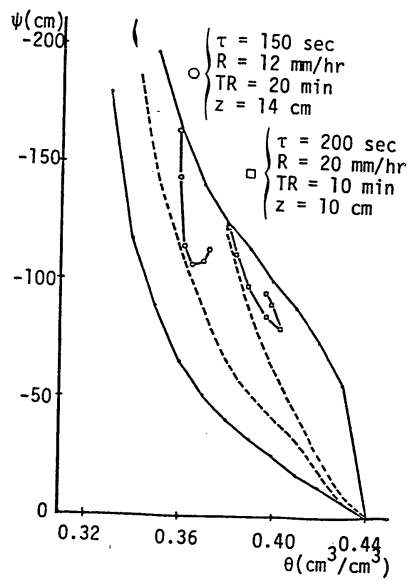

図-8Case2の計算結果による $\theta-\psi$ 関係(点線および上、下端 の実線は実験値、Topp ${ }^{5}$ 'より) 


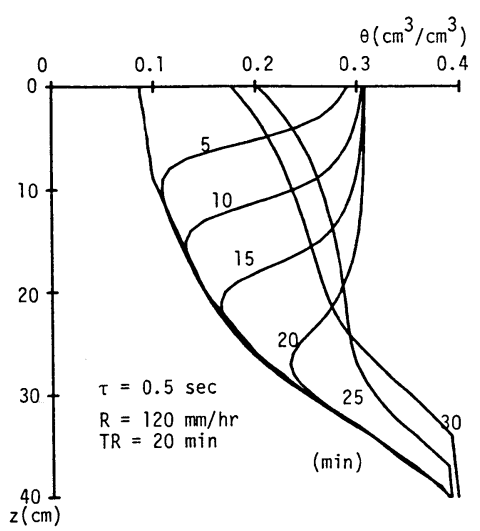

(a) $\tau=0.5 \mathrm{sec}$

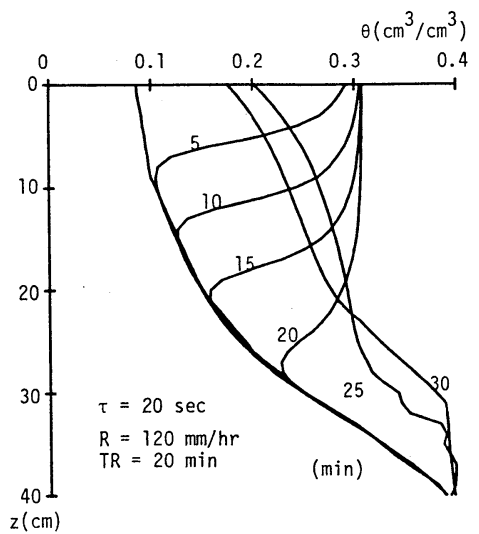

(b) $\tau=20 \mathrm{sec}$

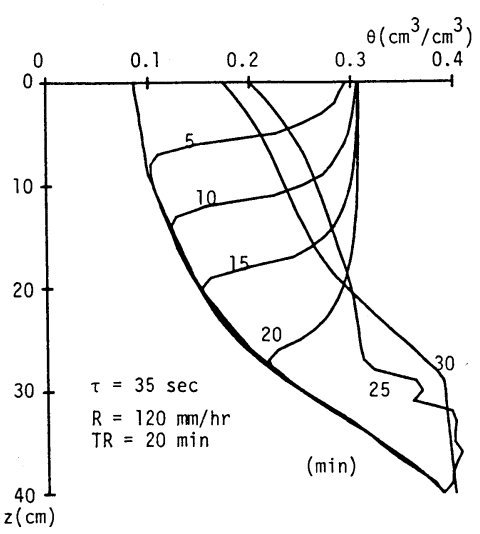

(c) $\tau=35 \mathrm{sec}$

图-9日分布の時間変化(Case 3)

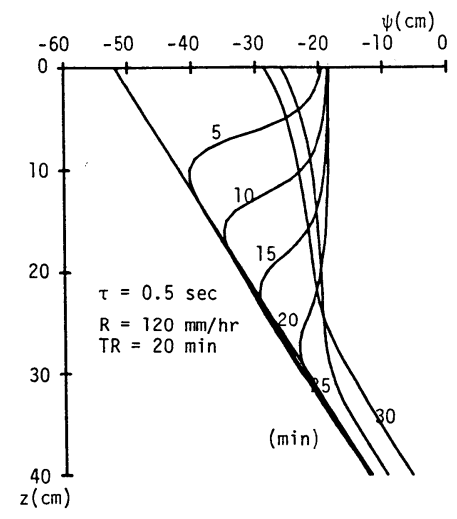

(a) $\tau=0.5 \mathrm{sec}$

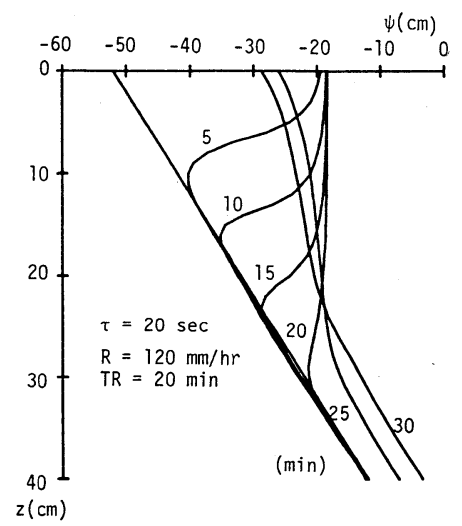

(b) $\tau=20 \mathrm{sec}$

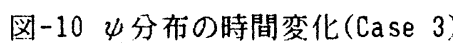

c)Case 3: 図-9,10,11はCase 30計算結果を示すものである。従 来、体積含水率 $\theta$ に関しては飽和一不飽和を統一して計算できない とされていたが、図-9に示す地下水面の上昇に見られるように土の わずかの圧縮性を考慮することにより $\theta$ に関しても飽和一不飽和領 域の統一した扱いが可能になったことがわかる。次に、初期状態が 自然な状態に近い静止状態からの計算においても、新しい方程式で ヒステリシスを考虑することによって りが見られる。また、ヒステリシスルーブも同様に描くことができ る。

\section{4..結論および考察}

（1）降雨の鉛直浸透におけるKinematic wave特性を検討すること により、土垬中のトレーサーの移動速度と水分量の移動速度との大 きな違いを説明することが可能となった。

（2）体積含水率 $\theta$ に関する計算においても、飽和一不飽和浸透の 統一した取扱が可能となつた。

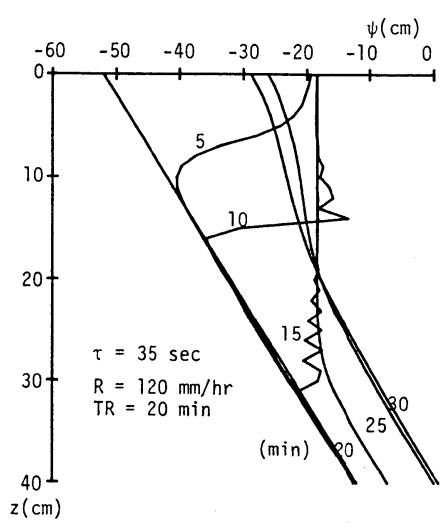

(c) $\tau=35 \mathrm{sec}$

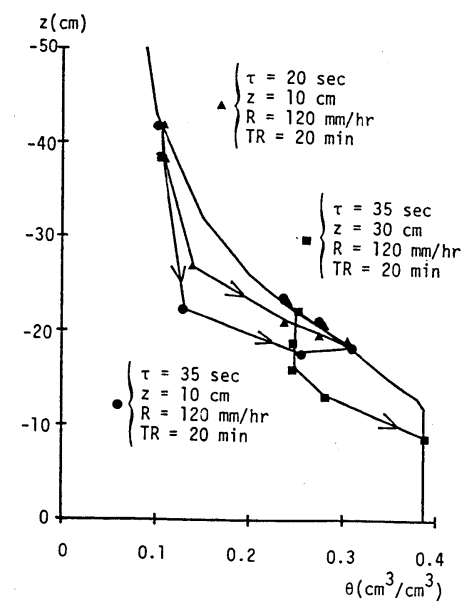

图-11 Case3の計算結果による $\theta-\psi$ 関係 
（3）不飽和浸透におけるヒステリシスの効果を方程式自体に組み込むという方法で与え、その基礎式を 導いた。さらに、その新しい方程式を数値計算によって解くことでヒステリシス現象を表現できることが 解っただけでなく、従来の移流分散型の方程式に新たに波動としての特性が加わってきた。これにより、 非常に速い圧力の伝播現象が現れるようになった。この現象に関しては次のように説明できる。

(9)式の鉛直一次元方向のみを表現すると次式となる。

$$
\tau C(\psi) \frac{\partial^{2} \psi}{\partial t^{2}}+C(\psi) \frac{\partial \psi}{\partial t}+\frac{d k(\psi)}{d \psi} \frac{\partial \psi}{\partial z}=\frac{\partial}{\partial z}\left\{k(\psi) \frac{\partial \psi}{\partial z}\right\}
$$

この(10)式において

$$
\begin{aligned}
& \frac{\partial}{\partial t} \simeq \frac{d k(\psi)}{d \psi} \frac{\partial}{\partial z} \\
& \frac{\partial}{\partial z}\left\{k(\psi) \frac{\partial \psi}{\partial z}\right\} \simeq k(\psi) \frac{\partial^{2} \psi}{\partial z^{2}}
\end{aligned}
$$

のような仮定が考えられるが、これらを(10)式に代入すると次式を得る。

$$
\left.c(\psi) \frac{\partial \psi}{\partial t}+\frac{d k(\psi)}{d \psi} \frac{\partial \psi}{\partial z}=\left[k(\psi)-\frac{\tau}{c(\psi)} \frac{d k(\psi)}{d \psi}\right\}^{2}\right] \frac{\partial^{2} \psi}{\partial z^{2}}
$$

この(13)式の右辺て

$$
\left.k(\psi)-\frac{\tau}{c(\psi)} \frac{d k(\psi)}{d \psi}\right\}^{2}<0
$$

の場合には負の拡散となり、不安定現象が発生する。これは、数学的には基本式が、拡散タイプから波動 タイプヘ変化した事に相当している。この不安定現象によって、上記の圧力伝播が生じると考えられる。 著者らは、この非常に速い压力の伝播が毛管水帯上縁付近の毛管水と毛管ポテンシャルの均衡を壊し、降 雨に対する地下水位の以上に速い応答を引き起こすのではないかと考えている。

謝辞：本研究は文部省科学研究費(代表、山田正)より補助を受けている。さらに本研究の遂行に当り、 北大、舆谷川和義博士、並びに道口敏幸技官より貴重な助言と助力を得ている。ここに記して深く感謝の 意を表す。

参考文献

(1) U.Zimmermann, K.O. Münnich and W.Roether: Dounward Movement of Soil Moisture Traced by Mean $S$ of Hydrogen Isotopes, Isotope Techniques in The Hydrologic Cycle, pp28-36, 1967.

(2) L.J.Andersen and T.Sevel: Six Years' Environmental Tritium Profiles in The Unsaturated an d Saturated Zones, Grønh $\phi j$, Denmark, Isotope Techniques in Groundwater Hydrogy, Vol.1,pp3-20, 1984.

(3) T.Aneblom and G.Persson: Studeis of The Variations in Water Content in The Unsaturated Zo ne of an ESKER, Nordic Hydrological Conference and Second Nordic IHP Meeting, 1978.

（4）西垣誠：飽和不飽和領域内の土中水の浸透特性に関する 2、3の考察, 土質工学会論文報告集, V 01.23 , No.3, 1983.

(5) G.C.Topp: Soil Water Hysteresis in Silt Loam and Clay Loam Soil, Water Resources Research ,v01.7 No.4, pp914-920, 1971.

（6）赤井浩一、大西有三、西垣誠：有限要素法による飽和一不飽和浸透流の解析, 土木学会論文報告集第 264号, Pp87-96, 1977.

(7) G.B.Whitham: Linear and Nonlinear waves, New York:Wiley, 1974.

（8）山田正、小林稔：降雨の鉛直浸透における Kinematic wave 特性とヒステリシスの効果を考虑した新 しい不飽和浸透方程式の解の特性, 第42回年次学術講演会講演概要集, pp122-123,1987. 